arrives with vaginal discharge, and the 40 year old worries about a chest pain. If the meaning or value of these symptoms is wrongly assessed a patient may be sent away with an issue dangerously unresolved or a physical symptom distressingly and expensively investigated.

Family doctors have always recognised these associations, but they have recently been given firmer scientific basis. In general practice psychosocial factors have been shown to play a large part in many adult consultations ${ }^{4}$ and in up to half the encounters with children. ${ }^{5}$ Similar patterns are suggested by studies of adolescents. ${ }^{6}$

Bereavement has now been extensively researched; after an important death the survivor is more at risk, has more symptoms, and is more likely to attend at surgery in the subsequent months. ${ }^{7} \mathrm{~A}$ woman who loses her mother early in life may be more vulnerable to depression when later she herself becomes a mother with young children. ${ }^{8}$ Even positive life changes, like marriage or having a baby, may of necessity contain some loss (such as a reduction of privacy or independence). Peing aware of these factors may help doctors make more sense of many of the tribulations and troubles seen in primary care, where conventional classifications of psychological disorder seem less relevant and useful than in psychiatric practice. ${ }^{9}$

Impressive though these research findings may seem in specialist journals, the general practitioner still depends mostly on his own intuition and experience to make sense of what he sees. Not enough attention has been given to description in practice research, for in many ways we are still like the early pathologists, trying to identify new patterns of complaint and attendance. Plays and novels may be a great stimulus to inquiry: in this context Staying $\mathrm{On}$ is more important than switching off. ${ }^{10}$ But the most important source of education available to every practising doctor remains himself and his own patients-provided that he takes the opportunity from time to time to ponder and discuss. ${ }^{11}$ To help this process the $B M F$ has asked some doctors to identify life changes that they consider important to their practice of medicine; each will start the article with a personal account of the problem under discussion. This series begins today ( $p$ 1584).

Whether the patient's basic complaint is physical or emotional the doctor's work starts with imaginative listening, so that the patient feels that his condition is being taken seriously. The timing of attendance or symptoms may give valuable clues. The doctor may notice an anniversary, a significant birthday, or an important association for the symptom. ${ }^{12} 13$

Reactions may be delayed after an important life event because the patient is coping in some senses too well. Something small then comes as the last straw, or strength ebbs when the patient has stopped being so active or responsible. What the patient himself makes of the complaints and how they fit the context of his life may help to unravel the meaning for all concerned. With attention being paid, and appropriate physical checks made, the task in general practice is often one of excluding and explaining, anticipating, and preventing. The doctor should discuss the range of normal experience, how things may develop or change further, what can be expected, and what should be avoided. ${ }^{14}$ With experience much of this can be fitted into usual practice time limits, since the patient may consolidate his thoughts between consultations. What more remains to be done depends on the individual and the severity of the disturbance.

Counselling or similar intervention has been shown to be effective for those particularly at risk, such as vulnerable widows or widowers. ${ }^{15}$ A planned programme of support from members of the primary care team should always be offered. The impact of a disturbing event may be minimised, and anxiety and fear may even be turned into contentment by good planning and family support-for instance, when a baby is to be born or a death expected. Relief from responsibility may be provided, and time given for the patient or the family to talk through the events and express their emotions. The doctor must always be on the alert for reactions that are distorted and offer help before a pathological or destructive pattern is established. The skills of specialists, trained therapists, peer support groups, or voluntary helping agencies should be considered. The doctor should not forget the needs of caring relatives and practice staff. Life changes affect us all. They should be milestones, not millstones.

\section{ROGER HIGGS}

General Practitioner, and

Director of General Practice Studies,

King's College School of Medicine and Dentistry,

London SE5 8RX

1 Tuckett D. Becoming a patient. In: Tuckett D, ed. An introduction to medical sociology. London: Tavistock, 1976:159-89.

${ }^{2}$ Parkes CM. Psychosocial transitions: a field for study. Social Science and Medicine $1971 ; 5: 101-15$.

${ }^{3}$ Higgs R. Psychosocial problems 1-4, postgraduate partwork series. Horton Kirby: Modern Medicine Publications, 1983.

4 Goldberg DP, Blackwell B. Psychiatric illness in general practice. Br Med f 1970;ii:439-43.

${ }^{5}$ Bailey V, Graham P, Baniface D. How much child psychology does a general practitioner do ? F $R$ Coll Gen Pract 1978;28:621-6.

${ }^{6}$ Bewley BR, Higgs RH, Jones A. Adolescents in inner city general practice. $\mathcal{F}$ Coll Gen Pract (in press).

7 Raphael B. Anatomy of bereavement. New York: Basic Books, 1983.

8 Brown GW, Harris T. Social origins of depression. London: Tavistock, 1978.

${ }^{9}$ Clare AW. Problems of psychiatric classification in general practice. In: Clare AW, Lader MH, eds. Psychiatry and general practice. London: Academic Press, 1982:15-25.

10 Scott P. Staying on. London: William Heinemann, 1977.

11 Campbell A, Higgs R. In that case. London: Darton Longman and Todd, 1982.

12 Bornstein PE, Clayton PJ. The anniversary reaction. Diseases of the Nervous System $1972 ; 33: 470-2$.

${ }^{13}$ Birchnall J. In search of correspondences between age at psychiatric breakdown and age at death. "Anniversary reactions." $\mathrm{Br} \mathcal{F} \mathrm{Med}$ Psychol $1981 ; 54: 111-21$.

14 Royal College of General Practitioners. Prevention of psychiatric disorders in general practice. London: Royal College of General Practitioners, 1981. (Report from General Practice, No 20.)

15 Parkes CM. Bereavement counselling: does it work ? $\mathrm{Br} M e d \mathcal{f} 1980 ; \mathbf{2 8 1}$. 3-6.

\section{Prognosis in sarcoidosis}

Sarcoidosis usually affects young people and may be symptomless and discovered by chance. The natural questions are "What is it?" and "Will it get better?" We still cannot answer the former, but a recent study of over 800 patients attending a special sarcoidosis clinic in London has provided a useful summary of the clinical course and prognostic factors in sarcoidosis ${ }^{1}$ and has largely reaffirmed the experience of previous, smaller series. ${ }^{2-4}$

Nearly all patients with sarcoidosis have abnormal chest radiographs when first seen. These changes will eventually disappear in just over half, but the chances of resolution and remission of disease depend on both the radiological appearances at presentation and their subsequent behaviour. 
Hilar lymphadenopathy alone (stage I) is found in two thirds of patients and has the best prognosis: the chest radiograph eventually returns to normal in $60 \%$. Of those who improve in this way the change occurs within one year in nearly $60 \%$ and within two years in three quarters. ${ }^{3}$ After spontaneous improvement relapse is very unusual. One fifth of patients presenting with stage I disease progress to stage II (pulmonary infiltration and hilar lymphadenopathy) and $6 \%$ go on to stage III disease (pulmonary infiltration alone), when only a third of radiographs will eventually resolve.

Of patients presenting with stage II disease, $40 \%$ show eventual clearing of the chest radiograph, but it is slow, with the improvement occurring within one year in only a quarter and within two years in half. ${ }^{3}$ The chance of improvement in patients presenting with stage III disease is even lower: only one third improve within two years or show eventual clearing of the chest radiograph.

Erythema nodosum is the most common extrathoracic manifestation of sarcoidosis, being a presenting feature in a third of cases. More frequent in women and whites, it always resolves, usually within one month. Erythema nodosum is often associated with acute arthralgia and hilar lymphadenopathy and carries a particularly good prognosis- $-85 \%$ of patients with this disease pattern show remission of their sarcoidosis within two years. In contrast, other sarcoid skin lesions such as plaques, infiltration of scars, lupus pernio, and maculopapular rashes are insidious in onset and persistent and are associated with chronic disease and a poor prognosis. Resolution of intrathoracic changes occurs in only a third of patients with this pattern, and only $15 \%$ show remission of disease within two years.

Ocular lesions (in $27 \%$ of all cases) can take the form of acute anterior uveitis (more often seen in women and associated with erythema nodosum, hilar lymphadenopathy, and a very good prognosis) or chronic uveitis, marked by frequent relapse. Disease in other organs such as the heart, parotids, liver, spleen, bones, upper respiratory tract, ${ }^{5}$ and the central nervous system is usually associated with chronicity and a low two year remission rate. The site of disease is important: facial nerve palsy may well resolve without sequelae, but brain stem lesions may cause disabling permanent disability; sudden death occurred in 48 of 197 patients with sarcoid heart disease, presumably related to damage to the conducting system. ${ }^{6}$

Age and race influence prognosis. Older patients do less well $^{3}$ as do blacks when compared with whites. ${ }^{2}$ Blacks are less likely to present with erythema nodosum and have more chronic skin lesions. The reported mortality from sarcoidosis is about $4-5 \% \cdot{ }^{12} 7$ Death is usually due to pulmonary fibrosis causing respiratory or cardiac failure. Cor pulmonale is a very poor prognostic sign.

There is no agreement on when sarcoidosis should be treated or for how long. Corticosteroids are widely used but without proof that they affect the natural history of the disease, alter prognosis, or even prevent the development of pulmonary fibrosis. Although both retrospective and prospective studies have shown that treatment produces early clinical, physiological, and radiographic improvement, no benefit is seen at long term follow up when treated patients are compared with untreated controls. ${ }^{8-11}$ The problem is that our conventional methods of assessing patients with sarcoidosis (by clinical means, physiological measures, and radiographic staging) are too crude and unreliable to identify individual patients with active and aggressive disease who might benefit (theoretically at least) from early treatment with corticosteroids.

Active pulmonary sarcoidosis is characterised by a lymphocytic alveolitis, which precedes and probably mediates the formation of pulmonary granulomas and fibrosis. ${ }^{12-14}$ Measurement of serum angiotensin converting enzyme concentrations, lung scanning with gallium-67, and bronchoalveolar lavage have been used to try to assess the intensity of the alveolitis of active pulmonary sarcoidosis. ${ }^{14-16}$ In one study of 19 patients with untreated pulmonary sarcoidosis an episode of "high intensity" alveolitis (shown by increased gallium-67 uptake and a greater yield of lymphocytes on lavage) predicted functional deterioration within six months $87 \%$ of the time, whereas "low intensity" alveolitis preceded deterioration only $8 \%$ of the time. ${ }^{14}$ Such methods may be leading us nearer to predicting activity and prognosis and so allowing more rational decisions on treatment. In the mean time clinicians must base their decisions about treatment on clinical experience. In practice few doctors would treat patients with stage I disease and most would merely observe asymptomatic patients with stage II lesions. The decision to treat stage II and stage III pulmonary disease is usually made because of progressive symptoms, impaired lung function, or deteriorating radiographic appearances. Active ocular, cardiac, and neurological sarcoidosis are regarded as indications for treatment in the hope that steroids will reduce inflammation and prevent fibrosis in vital structures.

JOHN T MACFARLANE

Consultant Physician,

City Hospital,

Nottingham NG5 1PB

${ }^{1}$ Neville E, Walker AN, James DG. Prognostic factors predicting the outcome of sarcoidosis: an analysis of 818 patients. Q $\mathcal{F}$ Med $1983 ; \mathbf{5 2}$ : 525-33.

2 Sones M, Israel HL. Course and prognosis of sarcoidosis. Am $\mathfrak{F} \mathrm{Med}$ $1960 ; 29: 84-93$.

${ }^{3}$ Romer FK. Presentation of sarcoidosis and outcome of pulmonary changes. Dan Med Bull $1982 ; 29: 27-32$.

Scadding JG. Sarcoidosis. London: Eyre and Spottiswoode, 1967.

${ }^{5}$ Neville E, Mills RGS, Jash DK, et al. Sarcoidosis of the upper respiratory tract and its association with lupus pernio. Thorax $1976 ; 31: 660-4$.

${ }^{6}$ Fleming HA, Bailey SM. Sarcoid heart disease. $\mathcal{F} R$ Coll Physicians Lond $1981 ; 15: 245-53$.

7 James DG, Neville E, Siltzbach LE, et al. A worldwide review of sarcoidosis. Ann NY Acad Sci 1976;278:321-34.

${ }^{8}$ Johns CJ, Macgregor MI, Zachary JB, Ball WC. Extended experience in the long term corticosteroid treatment of pulmonary sarcoidosis. Ann NY Acad Sci 1976;278:722-9.

9 Selroos O, Sellergren TL. Corticosteroid therapy of pulmonary sarcoidosis. Scand $\mathcal{F}$ Respir Dis 1979;60:215-21.

10 Harkleroad LE, Young RL, Savage PJ, et al. Pulmonary sarcoidosis. Long term follow up of the effects of steroid therapy. Chest $1982 ; 82: 84-7$.

11 Thrasher DR, Briggs DD. Pulmonary sarcoidosis. Clin Chest Med $1982 ; 3: 537-63$.

12 Rosen Y, Athanassiades TJ, Moon S, Lyons HA. Non granulomatous interstitial pneumonitis in sarcoidosis: relations to the development of epithelioid granulomas. Chest 1978;74:122-5.

${ }^{13}$ Bernaudin JF, Lacronique J, Soler P, et al. Alveolitis and granulomas: sequential onset and evolution in pulmonary sarcoidosis [Abstract]. Bull Eur Physiopathol Respir 1981;17:27.

${ }^{14}$ Keogh BA, Hunninghake GW, Line BR, Crystal RG. The alveolitis of pulmonary sarcoidosis. Am Rev Respir Dis 1983;128:256-65.

15 Poole GW. The diagnosis of sarcoidosis. Br Med f 1982;285:321-2.

16 Davies BH. Sarcoidosis-a gleam of light. Thorax 1983;38:165-7. 